\title{
Review
}

\section{Stroke Epidemiology in Oceania: A Review}

\author{
Narayanaswamy Venketasubramanian \\ Raffles Neuroscience Centre, Raffles Hospital, Singapore, Singapore
}

\section{Keywords}

Stroke $\cdot$ Oceania $\cdot$ Epidemiology $\cdot$ Burden

\begin{abstract}
Background and Purpose: Oceania, comprising the regions Australasia, Melanesia, Micronesia, and Polynesia, is home to 42 million living in 8.5 million square kilometres of land. This paper comprises a review of the epidemiology of stroke in countries in this region. Methods: Information on epidemiology of stroke in Oceania was sought from data from the Global Burden of Disease (GBD) study (incidence, mortality, incidence:mortality ratio [IMR], prevalence, disability-adjusted life-years [DALYs] lost due to stroke, and subtypes), World Health Organization (WHO) (vascular risk factors in the community), and PubMed (incidence, prevalence, and stroke subtypes). Data were analyzed by region to allow inter-country comparison within each region. Results: In 2010, ageand sex-standardized stroke mortality rates were lowest in Australasia $(29.85-31.67 / 100,000)$ and highest in Melanesia and Micronesia (56.04-187.56/100,000), with wide ranges especially in Melanesia. Incidence rates were lowest in Australasia (101.36-105.54/100,000), similarly high elsewhere. Standardized IMR (0.98-3.39) was the inverse of the mortality rates and mirrored the prevalence rates (202.91$522.29 / 100,000)$. DALY rates $(398.22-3,781.78 / 100,0000)$ mirrored the mortality rates. Stroke risk factors show a variable pattern - hypertension is generally the most common medical risk factor among males (18.0-26.6\%), while among
\end{abstract}

females, diabetes mellitus is the most common in Micronesia and Polynesia (21.5-28.4\%). Among the lifestyle factors, current smoking is the most common in Melanesia among males, while obesity is generally the most common factor among females. Ischaemic stroke comprises $70 \%$ of stroke subtypes. Trend data show significant falls in standardized mortality rates and DALYs in most regions and falls in incidence in almost all countries. There is significant economic impact, particularly due to young strokes; some ethnicities are at higher risk than others, for example, Maoris and $\mathrm{Pa}$ cific Islanders. Conclusions: Stroke is a major healthcare problem in Oceania. Variations in stroke epidemiology are found between countries in Oceania. Data are lacking in some; more research into the burden of stroke in Oceania is needed. With the expected increase in life expectancy and vascular risk factors, the burden of stroke in Oceania will likely rise. Some of the disparities in stroke burden may be addressed by great investment in healthcare.

(c) 2021 S. Karger AG, Base

\section{Introduction}

Stroke is a major cause of death and disability in many counties of the world. In 2016, globally, there were nearly 80.1 million stroke survivors, 5.5 million deaths due to stroke, 116.4 million disability-adjusted life-years (DALYs) lost because of stroke, and 13.7 million new strokes [1]. The greatest burden by number of deaths and

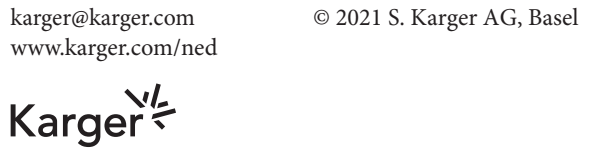

Narayanaswamy Venketasubramanian

Raffles Hospital, Raffles Neuroscience Centre 585 North Bridge Rd.

Singapore 188770 (Singapore)

drnvramani@gmail.com 


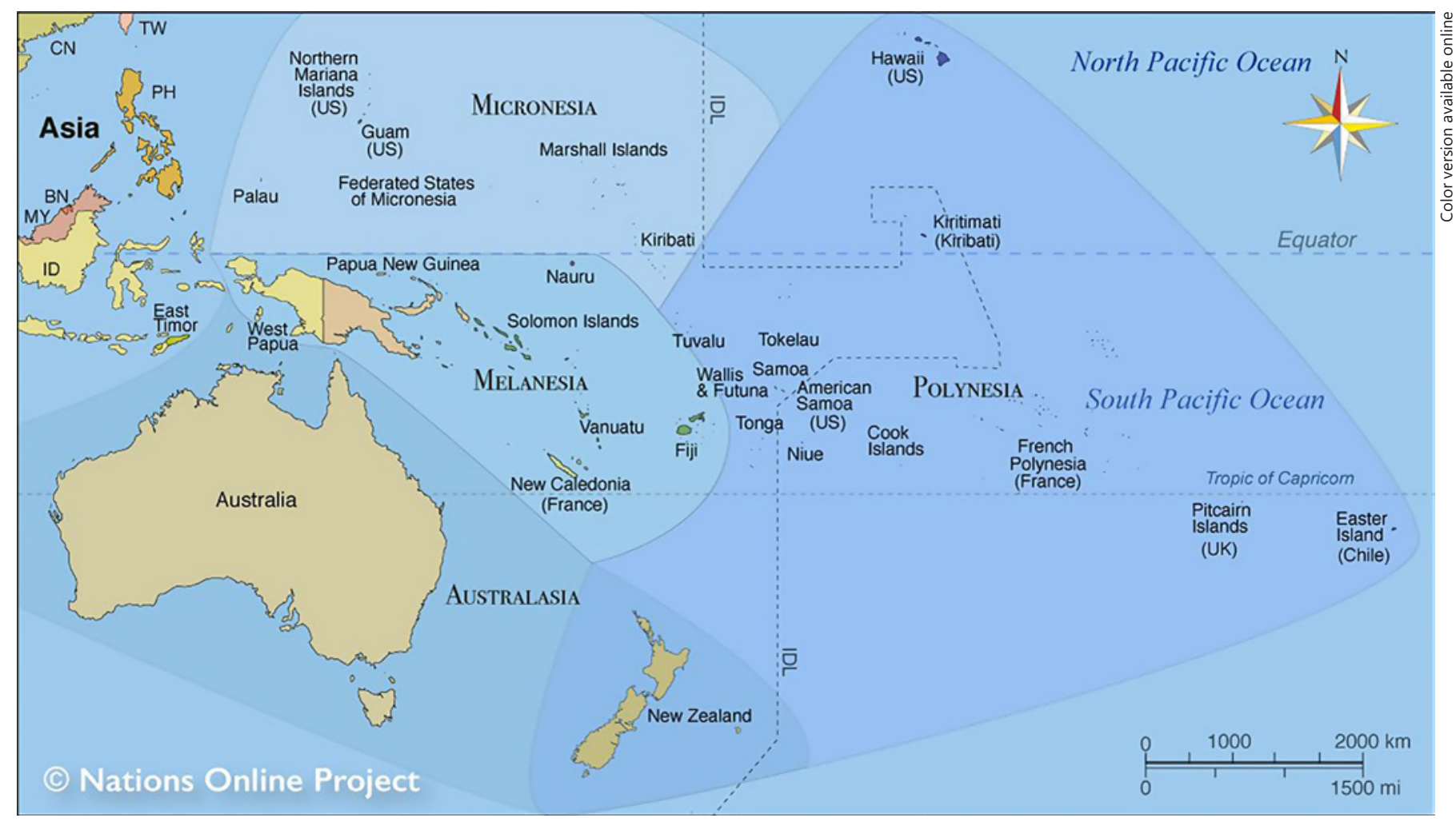

Fig. 1. Oceania and its geographical regions - Australasia, Melanesia, Micronesia, and Polynesia.

DALYs lost due to stroke globally is in East, South, and South East Asia - the epidemiology of stroke in Asia has been recently reviewed [2].

Oceania lies in the south-east region of the Asia-Pacific. Occupying 8.5 million square kilometres of land and home to 42 million people, the 14 countries of Oceania are grouped by the United Nations into 4 geographical regions: Australasia (Australia and New Zealand), Melanesia (Fiji, Papua New Guinea [PNG], Solomon Islands, and Vanuatu), Micronesia (Kiribati, Marshall Islands, Federated States of Micronesia, Nauru, and Palau), and Polynesia (Samoa, Tonga, and Tuvalu) [3] (Fig. 1). They are largely islands, in various stages of economic development.

There have been previous reviews of stroke epidemiology that addressed countries in the region. One only discussed mortality and only included Australia and New Zealand [4]. Another only investigated vascular risk factors, and Oceanian countries were excluded [5]. There have been other papers investigating vascular risk factors in the region, but not all Oceanian countries were included [6-10]. Also, these studies were published some time ago between 2001 and 2011 [4, 6-10], with one in 2015 [5].
This paper is a review of the recent epidemiology of stroke in the countries of Oceania by region, including mortality, incidence, prevalence, DALYs lost, stroke subtypes, risk factors, and trends, based on data from the Global Burden of Disease (GBD) study, World Health Organization (WHO), and recent major publications from these countries. A greater understanding of the burden stroke in this part of the world would assist in demonstrating the magnitude of the problem of stroke and its diversity and be a resource for healthcare planning and resource allocation.

\section{Methods}

The PubMed database was searched for all publications from the time of entry into the database to December 31, 2019. The search terms used were 'stroke' with the operator "AND" with any ("OR") of the following terms: "burden," "epidemiology," "mortality," "incidence," prevalence," "subtype," and "risk factors." The operator "AND" was then used with the name of each country in Oceania. The abstracts were reviewed for content and relevance, and data on stroke epidemiology were extracted. Where possible, the original papers were requested for and reviewed. The most recent study from each country or recent review papers from that 
Table 1. Mortality, incidence, IMR, prevalence, and DALYs lost due to stroke (with 95\% CI)

\begin{tabular}{|c|c|c|c|c|c|}
\hline Australia & $29.85(25.60-35.02)$ & $101.36(84.04-122.90)$ & 3.39 & $522.29(309.06-813.49)$ & $398.22(346.70-458.35)$ \\
\hline New Zealand & $31.67(26.72-35.40)$ & $105.54(86.91-126.69)$ & 3.32 & $473.04(448.92-500.37)$ & $440.38(384.74-478.29)$ \\
\hline \multicolumn{6}{|l|}{ Melanesia } \\
\hline Indonesia & $193.34(168.69-208.35)$ & $259.65(175.24-370.31)$ & 1.34 & $396.04(237.59-612.99)$ & $3,382.24(2,918.80-3,666.95)$ \\
\hline Solomon Islands & $187.56(143.67-267.62)$ & $182.90(118.81-267.89)$ & 0.98 & $204.51(120.41-340.24)$ & $3,781.78(2,811.86-5,495.05)$ \\
\hline Vanuatu & $183.60(131.26-263.90)$ & $185.90(127.89-270.44)$ & 1.01 & $202.91(116.02-331.86)$ & $3,595.80(2,456.88-5,241.80)$ \\
\hline \multicolumn{6}{|l|}{ Micronesia } \\
\hline Kiribati & $168.12(137.34-198.46)$ & $179.05(115.63-267.97)$ & 1.07 & $219.38(132.49-355.34)$ & $3,675.19(2,850.18-4,398.46)$ \\
\hline Marshall Islands & $125.04(104.10-145.14)$ & $175.45(115.75-244.07)$ & 1.40 & $248.13(146.67-390.19)$ & $2,563.92(2,124.88-2,957.88)$ \\
\hline Samoa & $74.32(58.10-99.19)$ & $164.62(109.49-238.42)$ & 2.22 & $329.12(199.31-523.50)$ & $1,384.48(1,089.71-1,879.78)$ \\
\hline Tonga & $54.35(46.61-67.20)$ & $160.61(104.85-236.40)$ & 2.96 & $377.88(225.93-598.34)$ & $968.72(835.72-1,216.40)$ \\
\hline Tuvalu & na & na & na & na & na \\
\hline
\end{tabular}

IMR, incidence:mortality ratio; DALYs, disability-adjusted life-years.

country were preferred over older publications. Data on incidence, prevalence, and stroke subtypes, as well as stroke risk factors, were sought from community-based studies. Data on stroke subtypes and vascular risk factors among hospitalized stroke patients were also looked for. Data on stroke mortality, incidence, prevalence, and DALYs lost were obtained from the Global Burden of Disease (GBD) study, while data on vascular risk factors in the community were obtained from the World Health Organization (WHO) database. The data were then tabulated and stratified by geographical regions within Oceania. Data for Indonesia were also entered for comparison as it is geographically adjacent to Oceania - the western part of the island New Guinea called Western New Guinea is part of Indonesia (and thus Asia) while the eastern part called Papua New Guinea is part of Oceania.

\section{Results and Discussion}

\section{Mortality}

Based on data from the GBD study [11], there is a wide range in the age- and sex-standardized mortality rates in Oceania in 2010 (Table 1) - data were not available for some countries. The lowest rates are in Australasia, then double of that in Polynesia, and double to triple of that in Melanesia and Micronesia. There are wide ranges in mortality especially in Melanesia (low in PNG where it more resembled Polynesia and very high in Solomon Islands and Vanuatu and Indonesia) and to a lesser extent in $\mathrm{Mi}$ - cronesia. The varying rates may reflect differences in stroke incidence, disease severity, and quality of healthcare. Competing causes of death may give a falsely low rate of mortality attributable to stroke.

\section{Incidence}

Standardized stroke incidence data from the GBD study [11] show lower rates in Australasia, but similar higher rates elsewhere in 2010 - data points were missing for the same countries just as for the mortality data (Table 1 ). The variations seen may reflect differences in risk factor frequency, screening/detection, and level of control.

The pattern of the standardized incidence:mortality ratio (IMR) is the inverse of the mortality rates, being highest in Australasia, intermediate in Polynesia, and lowest in Melanesia (with the exception of PNG, where it more resembles Polynesia) and Micronesia. The ratio reflects the success or failure of strategies for stroke management in a specific region or country and provides a basis of comparison of the stroke systems if the case mix (age, gender, stroke subtypes, and stroke severity) is similar.

\section{Prevalence}

Data on standardized stroke prevalence in 2010 based on the GBD study [11] mirror the pattern seen for IMR, which is not unexpected - highest in Australasia, inter- 
Table 2. Vascular risk factors in the community

\begin{tabular}{|c|c|c|c|c|c|c|c|c|c|c|c|c|}
\hline \multirow[t]{2}{*}{ Region/country } & \multicolumn{2}{|c|}{$\begin{array}{l}\text { Hypertension } \\
\text { SBP }>140 \mathrm{~mm} \mathrm{Hg} \\
\text { and DBP }>90 \mathrm{~mm} \\
\mathrm{Hg}(2015) \text {, } \\
18+\text { years, } \%\end{array}$} & \multicolumn{2}{|c|}{$\begin{array}{l}\text { Diabetes mellitus } \\
\text { FBS }>7.0 \mathrm{mmol} / \mathrm{L} \\
\text { or on medication } \\
(2014), 18+\text { years, } \\
\%\end{array}$} & \multicolumn{2}{|c|}{$\begin{array}{l}\text { Hyper- } \\
\text { cholesterolaemia } \\
\text { TC } \geq 6.2 \mathrm{mmol} / \mathrm{L} \\
(2008), 25+\text { years, } \\
\%\end{array}$} & \multicolumn{2}{|c|}{$\begin{array}{l}\text { Insufficient } \\
\text { physical activity } \\
(2016), 18+\text { years, } \\
\%\end{array}$} & \multicolumn{2}{|c|}{$\begin{array}{l}\text { Obesity } \\
\text { BMI } \geq 30 \text { (2016), } \\
18+\text { years, \% }\end{array}$} & \multicolumn{2}{|c|}{$\begin{array}{l}\text { Current smoking } \\
(2013), \geq 15 \text { years, } \\
\%\end{array}$} \\
\hline & M & $\mathrm{F}$ & M & $\mathrm{F}$ & M & $\mathrm{F}$ & M & $\mathrm{F}$ & M & $\mathrm{F}$ & M & $\mathrm{F}$ \\
\hline \multicolumn{13}{|l|}{ Australasia } \\
\hline Australia & 18.0 & 12.3 & 6.8 & 5.0 & 14.8 & 17.3 & 27.0 & 33.6 & 29.6 & 28.4 & 14.9 & 11.3 \\
\hline New Zealand & 19.3 & 13.3 & 7.9 & 6.0 & 17.3 & 6.1 & 39.3 & 45.3 & 30.1 & 31.4 & 17.6 & 15.9 \\
\hline \multicolumn{13}{|l|}{ Melanesia } \\
\hline Fiji & 22.4 & 20.7 & 15.9 & 18.9 & 16.3 & 14.3 & 10.8 & 24.1 & 25.1 & 35.3 & 31.8 & 9.8 \\
\hline Papua New Guinea & 25.1 & 25.8 & 15.4 & 14.3 & 7.6 & 9.7 & 11.4 & 18.2 & 16.6 & 25.8 & na & na \\
\hline Indonesia & 24.3 & 23.1 & 7.4 & 8.0 & 6.4 & 8.9 & 23.5 & 21.7 & 4.8 & 8.9 & 63.0 & 3.5 \\
\hline Solomon Islands & 20.4 & 23.6 & 12.6 & 15.1 & 5.5 & 8.0 & 13.3 & 23.2 & 17.9 & 27.1 & na & na \\
\hline Vanuatu & 24.2 & 24.1 & 15.7 & 16.0 & 7.6 & 9.9 & 7.2 & 8.8 & 20.2 & 30.1 & na & na \\
\hline \multicolumn{13}{|l|}{ Micronesia } \\
\hline Kiribati & 24.0 & 19.0 & 22.0 & 22.6 & 6.2 & 8.9 & 34.5 & 45.8 & 41.6 & 50.4 & 51.8 & 31.6 \\
\hline Marshall Islands & 23.8 & 18.6 & 20.8 & 21.5 & 9.9 & 14.7 & 37.0 & 50.0 & 48.4 & 57.3 & na & na \\
\hline Micronesia FedS & 26.6 & 23.2 & 20.5 & 23.4 & 12.4 & 13.7 & 32.9 & 40.5 & 40.1 & 51.5 & na & na \\
\hline Nauru & 23.8 & 17.2 & 30.1 & 28.4 & 9.0 & 15.2 & 34.9 & 49.4 & 58.3 & 63.3 & 35.8 & 40.6 \\
\hline Palau & 25.7 & 20.0 & 24.8 & 21.6 & 15.9 & 17.9 & 28.3 & 53.3 & 51.8 & 58.8 & na & na \\
\hline \multicolumn{13}{|l|}{ Polynesia } \\
\hline Samoa & 26.6 & 21.0 & 22.7 & 26.6 & 6.1 & 9.4 & 8.2 & 17.2 & 39.3 & 55.0 & 34.0 & 15.5 \\
\hline Tonga & 25.4 & 21.8 & 21.9 & 26.4 & 14.2 & 12.3 & 8.5 & 25.9 & 41.4 & 54.5 & 38.0 & 10.2 \\
\hline Tuvalu & 26.1 & 21.2 & 23.2 & 24.3 & na & na & 17.5 & 37.2 & 47.0 & 56.2 & na & na \\
\hline
\end{tabular}

SBP, systolic blood pressure; DBP, diastolic blood pressure; FBS, fasting blood sugar; TC, total cholesterol; BMI, body mass index; M, male; F, female; na, not available. Insufficient physical activity: $<150$ min of moderate-intensity physical activity per week or $<75$ min of vigorous-intensity physical activity per week or equivalent. Current smoking: daily and non-daily or occasional cigarette smoking.

mediate in Polynesia, and lowest in Melanesia and Micronesia, again with the exception of PNG where it more resembles Polynesia (Table 1). Some data points were missing. As prevalence reflects the balance between incidence and mortality, a low prevalence may be due to low incidence or high mortality or both; conversely, a high prevalence may be due to high incidence or low mortality or both. Mortality from other illnesses among stroke survivors may give a falsely low stroke prevalence. Still, prevalence will reflect the status of disease in the community that healthcare services for chronic diseases need to care for.

\section{Morbidity}

The best measure of the burden of stroke is arguably the number of DALYs lost due to stroke. Based on data from the GBD study [11], there is a wide range of age- and sex-standardized stroke DALYs lost in Oceania in 2010 (Table 1) - there were some missing data points. Lowest rates are in Australasia, intermediate in Polynesia, and highest in Melanesia and Micronesia, again with the exception of PNG where it resembles Polynesia. DALYs lost reflect the net effects of premature mortality, incidence, and disability among prevalent cases, the latter possibly indicating the effects of stroke severity and rehabilitative services.

\section{Vascular Factors}

Increasing age, male gender, and genetics are nonmodifiable risk factors for stroke. The modifiable stroke risk factors are shown in Table 2, based on data from the WHO [12].

Hypertension is generally the most common medical risk factor and among males except in Nauru where diabetes mellitus is the most common. Among females, diabetes mellitus is the most common in Micronesia and Polynesia, while it is still hypertension in Melanesia and New Zealand and hypercholesterolaemia in Australia. Hypertension is more frequent in males except in PNG and Solomon Islands. Diabetes mellitus is more frequent among females in Polynesia and males in Australasia, but a mixed pattern between the sexes elsewhere. Hypercholesterolaemia is more frequent in females except in Fiji, New Zealand, and Tonga. Among the lifestyle factors, cur- 
Table 3. Stroke subtypes from community-based studies

\begin{tabular}{|c|c|c|c|c|c|c|}
\hline \multicolumn{7}{|l|}{ Australia } \\
\hline Adelaide, Leyden et al. [14] & 2013 & $318 / 148,000$ & $84(78-88)$ & $11(8-16)$ & $3(1-6)$ & $3(1-6)$ \\
\hline Melbourne, Thrift et al. [15] & 2009 & $1,035 / 306,631$ & $69.2(66.3-71.9)$ & $14.6(12.6-16.9)$ & $5.4(4.2-7.0)$ & $10.8(9.1-12.9)$ \\
\hline Melbourne, Thrift et al. [16) & 2001 & $381 / 133,816$ & $72.5(67.2-77.7)$ & $14.5(10.3-18.6)$ & $4.3(1.9-6.8)$ & $8.7(5.4-12.0)$ \\
\hline Auckland, Krishnamurthi et al. [18] & 2018 & $1,643 / 1,119.192$ & $81(79-82)$ & $13(11-15)$ & $5(4-6)$ & $1(0-2)$ \\
\hline
\end{tabular}

IS, ischaemic stroke; IPH, intra-parenchymal haemorrhage; SAH, subarachnoid haemorrhage; UNC, unclassified.

Table 4. Stroke subtypes based on the Global Burden of Disease (GBD) study

\begin{tabular}{|c|c|c|c|c|}
\hline \multirow[t]{2}{*}{ Region/country } & \multicolumn{2}{|l|}{ Female } & \multicolumn{2}{|l|}{ Male } \\
\hline & $\begin{array}{l}\text { ischaemic } \\
\text { stroke, } \%\end{array}$ & $\begin{array}{l}\text { haemorrhagic } \\
\text { stroke, \% }\end{array}$ & $\begin{array}{l}\text { ischaemic } \\
\text { stroke, } \%\end{array}$ & $\begin{array}{l}\text { haemorrhagic } \\
\text { stroke, \% }\end{array}$ \\
\hline \multicolumn{5}{|l|}{ Australasia } \\
\hline Australia & 65.41 & 34.59 & 67.99 & 32.01 \\
\hline New Zealand & 70.01 & 29.99 & 70.51 & 29.49 \\
\hline \multicolumn{5}{|l|}{ Melanesia } \\
\hline Fiji & 61.12 & 38.88 & 67.71 & 32.29 \\
\hline Papua New Guinea & 56.91 & 43.09 & 63.50 & 36.50 \\
\hline Indonesia & 63.02 & 36.98 & 62.00 & 38.00 \\
\hline Solomon Islands & 56.69 & 43.31 & 62.93 & 37.07 \\
\hline Vanuatu & 58.42 & 41.58 & 63.39 & 36.61 \\
\hline \multicolumn{5}{|l|}{ Micronesia } \\
\hline Kiribati & 62.52 & 37.48 & 64.52 & 35.48 \\
\hline Marshall Islands & 60.43 & 39.57 & 64.36 & 35.64 \\
\hline Micronesia FedS & 58.80 & 41.20 & 63.33 & 36.67 \\
\hline Nauru & - & - & - & - \\
\hline Palau & - & - & - & - \\
\hline \multicolumn{5}{|l|}{ Polynesia } \\
\hline Samoa & 59.44 & 40.56 & 63.65 & 36.35 \\
\hline Tonga & 61.38 & 38.62 & 66.94 & 33.06 \\
\hline Tuvalu & - & - & - & - \\
\hline
\end{tabular}

Haemorrhagic stroke includes intra-cerebral haemorrhage and non-traumatic subarachnoid haemorrhage.

rent smoking is the least common in Australia but most common in Kiribati among males; obesity is generally the most common factor among females. Overall, physical inactivity and obesity are more common among females than males, while cigarette smoking is more common among males. Knowledge of risk factors in each population would inform policy makers and healthcare planners on which factors should be targeted in that country and what appropriate preventive measures could be taken.

\section{Stroke Subtypes}

Information on stroke subtypes is available from community-based stroke incidence studies in Australasia [13-18]. The data from large community-based studies are shown in Table 3. Data on stroke subtypes from the Global Burden of Disease study [19] are shown in Table 4. The differences in stroke subtypes seen in the 2 data sets may be due to source of the data. GBD used coded data, systematic reviews, population surveys, and stroke regis- 

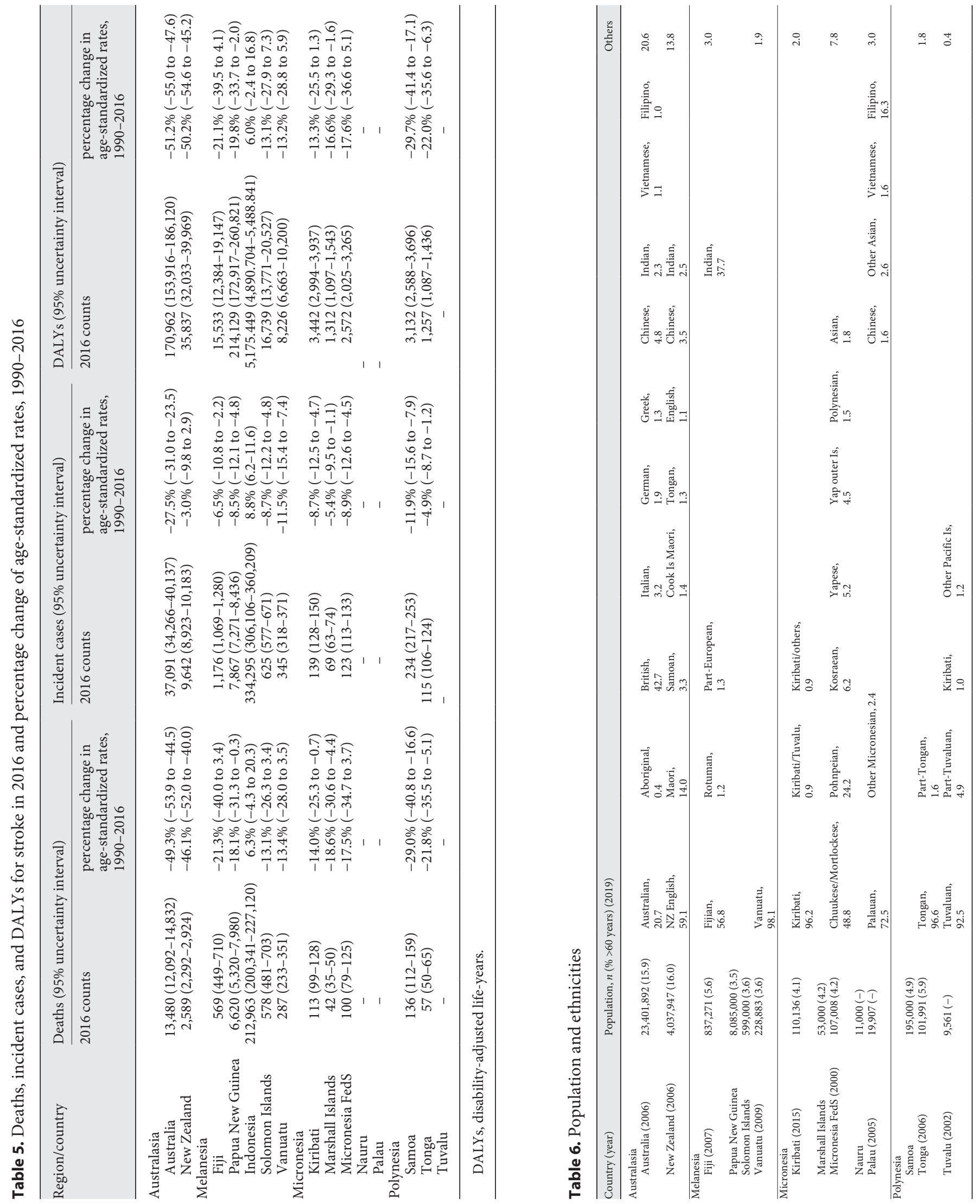
tries; the community-based studies use data of the individual participants from events occurring during the study. Ischaemic stroke is more common than haemorrhagic stroke, both among females and males, with haemorrhagic stroke comprising 30-43\% of stroke subtypes. This is similar to the $15-40 \%$ of stroke due to haemorrhage in Asia [2] and the 30\% in Western Europe, Latin America, and sub-Saharan Africa and higher than the $20 \%$ in Central and Eastern Europe and the 25\% found in high-income countries in North America, North Africa, and Middle East [19].

\section{Trends}

In recent GBD data, between 1990 and 2016 [1] (Table 5), there are significant falls in standardized mortality rates in Australasia, PNG, Micronesia, and Polynesia; falls in standardized incidence in all countries except $\mathrm{New}$ Zealand (which like Australia already had low incidence rates, vide supra); and falls in DALYs in Australasia, PNG, Marshall Islands, and Polynesia. This is consistent with global data showing falls in all 3 indices, except for East Asia which had a rise in incidence and South sub-Saharan Africa where there was no significant change in any of these parameters $[2,11]$.

This pattern of falling standardized incidence probably reflects the effectiveness and increased detection and better control of stroke risk factors, while the falling mortality could be the result of the fall in incidence, a decline in the severity of stroke, and better post-stroke care. This could fuel a rise in prevalence. However, the fall in DALYs is an encouraging indication of the falling incidence, better stroke management and rehabilitation to reduce poststroke disability, better patient access to healthcare and compliance, and improved governmental healthcare policies and services for stroke and stroke prevention.

Some of the countries in Oceania are considered lowermiddle income (Kiribati, PNG, Solomon Islands, and Vanuatu) [20]. With their economic transition towards a developed country, life span will be prolonged and risk factors such as hypertension, diabetes mellitus, hypercholesterolaemia, obesity, and cigarette smoking will likely become more frequent, raising stroke incidence. But with sufficient investment in healthcare in these developing countries, it is hoped the stroke burden will be kept low. It should be mentioned that all these four countries had registered significant falls in standardized stroke mortality incidence and DALYs between 1990 and 2016 (Table 5).

A case of interest is Kitava, also known as Trobriand Island, PNG. There were initially no cases of stroke there in 1993 [21]. This was attributed to their subsistence life- style, dietary habits, leanness, low diastolic pressure, and low serum cholesterol; their very low PI-1 activity may also have had a role to play [22]. However, in a later publication by the same author published in 2003 mentioned that stroke was not seen in the indigenous population before 1975, but subsequently accounted for 2 cases a week in Port Morresby General Hospital in the capital of PNG, possibly a new disease in this community [23]. Admittedly, the apparent absence of stroke reported earlier may be due to the lack of infrastructure to diagnose and report strokes.

\section{Economic Impact and Population Subgroups}

Stroke does have an economic impact. Early mortality and disability removes people from the work force. Studies from Fiji have provided evidence that the high economic burden is borne by Fiji from mortality due to stroke among young adults in terms of annual human capital loss [24, 25].

There are long-term costs of stroke, with financial benefits from reducing evidence-practice gaps in acute stroke care, including acute thrombolysis and stroke unit care [26-29]. The focus may need to be on primary prevention' especially blood pressure control $[30,31]$.

In multi-ethnic communities, some may be more at risk of stroke than others. The Maoris and Pacific peoples suffer an increased stroke burden; in New Zealand, nonEuropeans have longer hospital stays and 30-day case fatality after stroke [32-34]. Long-term falls in incidence and 1-year mortality are slower among Maoris and $\mathrm{Pa}$ cific people [35]. In Australia, the indigenous Aboriginal people too had higher incidence of stroke and increased frequency of risk factors and greater case fatality [36, 37]. Even though they had higher hospital bed days, there was a trend towards greater cost-effective stroke care in them [38]. Stroke mortality among Aboriginal people has also been falling [39].

\section{Geographical Variations}

There are wide variations in stroke burden in Oceania, as seen in the differences on mortality, incidence, prevalence, and morbidity (Table 1 ). The variations in vascular risk factors may have a role (Table 2). In addition, the proportion of elderly would also impact on numbers, though this effect is negated by age standardization. The highest proportion of elderly (aged $>65$ years) is in Australasia (16\%), compared to 3.5-5.9\% elsewhere in Oceania [40] (Table 6).

Ethnicity may have a role too. There is a mix comprising largely of Europeans and Asians in Australia, Europeans and Maoris in New Zealand, and Fijians and Indians 
Table 7. Healthcare services

\begin{tabular}{|c|c|c|c|c|c|c|}
\hline \multicolumn{7}{|l|}{ Australasia } \\
\hline Australia & HIC & 6.2 & 299 & 959 & \multicolumn{2}{|l|}{$\begin{array}{l}>1,300 \text { hospitals, private and public; responsibility of the } 6 \\
\text { states }\end{array}$} \\
\hline Fiji & LMIC & 2.6 & 43 & 224 & \multicolumn{2}{|l|}{$\begin{array}{l}2 \text { national hospitals, } 20 \text { regional hospitals, } 200 \text { healthcare } \\
\text { facilities, } 1 \text { private hospital }\end{array}$} \\
\hline Papua New Guinea & LMIC & 3.4 & 5 & 46 & \multicolumn{2}{|l|}{1 referral hospital, hospitals, dispensaries, clinics } \\
\hline Solomon Islands & LMIC & 8.4 & 22 & 205 & \multicolumn{2}{|l|}{$\begin{array}{l}1 \text { national referral hospital, } 7 \text { public hospitals, a few private } \\
\text { hospitals; area and rural health centres and nurse aid points }\end{array}$} \\
\hline Vanuatu & LMIC & 3.6 & 12 & 170 & \multicolumn{2}{|l|}{$\begin{array}{l}2 \text { referral hospitals, } 4 \text { provincial hospitals, } 30 \text { health centres, } \\
97 \text { dispensaries }\end{array}$} \\
\hline Nauru & LMIC & 3.6 & & & 1 national hospital & \multirow[t]{2}{*}{$\begin{array}{l}\text { Serious cases sent } \\
\text { to Australia }\end{array}$} \\
\hline Palau & & & & & & \\
\hline \multicolumn{7}{|l|}{ Polynesia } \\
\hline Samoa & LMIC & 6.3 & 48 & 185 & $\begin{array}{l}1 \text { national hospital; district hospitals, health centres; } \\
\text { increasing private healthcare }\end{array}$ & \multirow[t]{3}{*}{$\begin{array}{l}\text { Tertiary care links } \\
\text { with New } \\
\text { Zealand }\end{array}$} \\
\hline Tonga & LMIC & 4.4 & 56 & 388 & 4 hospitals, 14 healthcare centres & \\
\hline Tuvalu & LMIC & 17.3 & 109 & 582 & 1 hospital, 8 nurse-manned medical centres & \\
\hline
\end{tabular}

HIC, high-income country; LMIC, low- to middle-income country.

in Fiji, but largely local ethnicities in the rest of Oceania [41] (Table 6). It appears that the earliest settlers in Oceania were likely hunter gatherers from South East Asia who gradually moved into Papua (Papuans), Australia (indigenous Australians), and the Solomon Islands 50,000 years ago and then further eastward to Melanesi [42]. A second large migration about 3,000 years ago by Austronesianspeaking seafarers from Taiwan moved rapidly through this region and further eastward and north/south to populate Micronesia, Polynesia, and New Zealand (Maoris) [43]. The frequencies of diabetes mellitus and obesity are higher in Micronesia and Polynesia than in Melanesia, but stroke mortality and DALYs are lowest in Polynesia. These differing ethnic origins may contribute the diversity in culture and stroke patterns in Oceania.

Yet, another factor contributing to variations could be the differences in healthcare systems and services [44] (Table 7). The only high-income countries are in Australasia; the other regions are low- to middle-income countries. The proportion of GDP spent in health is highest in Tuvalu (17.3\%), intermediate in Australasia, Solomon Is- lands, Kiribati, and Samoa (6.2-8.4\%), and lower elsewhere. The highest proportion of doctors and nurses/ midwives is in Australasia. Most countries have at least 1 hospital and a number of healthcare centres - Australia and New Zealand provide tertiary care support for some Oceanian countries. Based on a 2019 national audit of acute stroke services in Australia, 82\% of hospitals provide thrombolysis, with endovascular thrombectomy available in 19 city-location hospitals; telehealth is used in $72 \%$ for acute assessment and treatment; stroke unit care is accessible to $67 \%$ but lower in regional as compared to city patients [45]. A 2016 survey of acute stroke services in New Zealand's District Health Boards showed that thrombolysis was available in $100 \%$ [46]; thrombectomy was available in only few centres [47]. A 2009 audit of acute stroke services in New Zealand showed that only $38 \%$ of DHBs had stroke units, with only $39 \%$ of all New Zealand patients being managed in a stroke unit, compared with $51 \%$ of all Australian patients on the audit day [48]. A greater investment in medical staff and facilities may have a positive impact on stroke burden in these countries. 


\section{Limitations and Strengths}

This paper has a few limitations. The data from the WHO, while available for almost all countries, are based on routinely available data from those countries or from population-based surveys or registries, which may have varying definitions of the vascular risk factors studied or methods of detection; national-level estimates may be based on extrapolation of smaller and subnational studies, with adjustment for urban-rural differences; where data were not available, statistical and regression models were used based on data from surrounding countries where possible; some data were from a decade ago, and in some instances, not available at all. While GBD study data are comprehensive and again based on routinely available administrative data or on possibly less-than-ideal community-based studies or registries, there are again no data for some countries; data from lower-income countries may not have high methodological quality; geospatial modelling may be needed; coding and clinical practices differ across countries; neuroimaging may not be sufficient, and there is insufficient granularity to differentiate data for intra-parenchymal from subarachnoid haemorrhage; the Rankin scale was used to index disability weights; silent strokes and vascular dementia were not included, and some data points were missing. Still, this paper has a number of strengths. It includes up-to-date reliable data from the authoritative GBD study and $\mathrm{WHO}$, which have searched extensively for sources of information and used robust study methods and modelling techniques to estimate and validate their data. The paper extracts and summarizes the available data and, by categorizing by region, allows for easy reading the key epidemiological data on stroke, useful for the clinicians, researchers, and healthcare planners.

\section{Conclusions}

Stroke is a major healthcare problem in Oceania. There are disparities in stroke mortality, incidence, prevalence, and morbidity. Data are lacking in some; more research into the burden of stroke in Oceania is needed. Governments and healthcare workers need to work together with an informed public to stem this growing epidemic. Greater attention to access to healthcare services, risk factor control, and an inclusive, coordinated, and culturally-appropriate approach would be needed for ethnic minorities $[37,49]$. Health and wellness coaching may be effective in primary prevention of stroke [50]. Patient-centred selfmanagement and rehabilitation has been shown to reduce post-stroke disability [51]. As life expectancy increases with the aging of people living in Oceania and the rise in the prevalence of vascular risk factors among economies in transition, the burden of stroke in Oceania will surely rise. Greater investment in healthcare may stem this tide.

\section{Conflict of Interest Statement}

The author has no conflicts of interest to declare.

\section{Funding Sources}

The author did not receive any funding.

\section{Author Contributions}

The author planned the study, performed the literature search, and wrote the paper.

\section{References}

1 GBD 2016 Stroke Collaborators. Global, regional, and national burden of stroke, 1990-2016: a systematic analysis for the Global Burden of Disease study 2016. Lancet Neurol. 2019;18:439-58.

2 Venketasubramanian N, Yoon BW, Pandian J, Navarro JC. Stroke epidemiology in South, East, and South-East Asia: a review. J Stroke. 2017;19:286-94.

3 UN Statistics Division. Methodology. Standard country or area codes for statistical use (M49). Overview https://unstats.un.org/unsd/methodology/m49/overview/.

4 Khor GL. Cardiovascular epidemiology in the Asia-Pacific region. Asia Pac J Clin Nutr. 2001; 10(2):76-80

5 Huxley RR, Hirakawa Y, Hussain MA, Aekplakorn W, Wang X, Peters SA, et al. Age- and sex- specific burden of cardiovascular disease attributable to 5 major and modifiable risk factors in 10 Asian countries of the Western Pacific Region. Circ J. 2015;79(8): 1662-74.

6 Asia-Pacific Cohort Studies Collaboration, Martiniuk AL, Lee CM, Lawes CM, Ueshima H, Suh I, Lam TH, et al. Hypertension: its prevalence and population-attributable fraction for mortality from cardiovascular disease in the Asia-Pacific region. J Hypertens. 2007; 25:73-9.

7 Asia Pacific Cohort Studies Collaboration; Lee CM, Huxley RR, Lam TH, Martiniuk AL, Ueshema H, Pan WH, et al. Prevalence of diabetes mellitus and population attributable fractions for coronary heart disease and stroke mortality in the WHO South-East Asia and Western Pa- cific regions. Asia Pac J Clin Nutr. 2007;16:18792.

8 Asia Pacific Cohort Studies Collaboration, Woodward M, Martiniuk A, Lee CM, Lam TH, Vanderhoorn S, Ueshima H, et al. Elevated total cholesterol: its prevalence and population attributable fraction for mortality from coronary heart disease and ischaemic stroke in the AsiaPacific region. Eur J Cardiovasc Prev Rehabil. 2008;15:397-401.

9 Asia Pacific Cohort Studies Collaboration Martiniuk AL, Lee CM, Lam TH, Huxley R, Suh I, Jamrozik K, et al. The fraction of ischaemic heart disease and stroke attributable to smoking in the WHO Western Pacific and South-East Asian regions. Tob Control. 2006; 15:181-8. 
10 Lee CM, Colagiuri S, Ezzati M, Woodward M. The burden of cardiovascular disease associated with high body mass index in the Asia-Pacific region. Obes Rev. 2011;12(5):e454-9.

11 Global Burden of Diseases, Injuries, and Risk Factors Study 2010 (GBD 2010) and the GBD Stroke Experts Group; Feigin VL, Forouzanfar MH, Krishnamurthi R, Mensah GA, Connor $\mathrm{M}$, Bennett DA, et al. Global and regional burden of stroke during 1990-2010: findings from the global burden of disease study 2010. Lancet. 2014;383:245-54.

12 World Health Organisation. Global Health Observatory data repository. Raised blood pressure (SBP $\geq 140$ OR DBP $\geq 90$ ), age-standardized (\%). Estimates by country [accessed 2019 Dec 31 http://apps.who.int/gho/data/view. main.2464ESTSTANDARD?lang=en.

13 Newbury J, Kleinig T, Leyden J, Arima H, Castle S, Cranefield J, et al. Stroke epidemiology in an Australian rural cohort (SEARCH). Int J Stroke. 2017;12(2):161-8.

14 Leyden JM, Kleinig TJ, Newbury J, Castle S, Cranefield J, Anderson CS, et al. Adelaide stroke incidence study: declining stroke rates but many preventable cardioembolic strokes. Stroke. 2013;44(5):1226-31.

15 Thrift AG, Dewey HM, Sturm JW, Srikanth VK, Gilligan AK, Gall SL, et al. Incidence of stroke subtypes in the North East Melbourne Stroke Incidence Study (NEMESIS): differences between men and women. Neuroepidemiology. 2009;32(1):11-8.

16 Thrift AG, Dewey HM, Macdonell RA, McNeil JJ, Donnan GA. Incidence of the major stroke subtypes: initial findings from the North East Melbourne Stroke Incidence Study (NEMESIS). Stroke. 2001;32(8):1732-8.

17 Anderson CS, Jamrozik KD, Burvill PW, Chakera TM, Johnson GA, Stewart-Wynne EG. Determining the incidence of different subtypes of stroke: results from the Perth Community Stroke Study, 1989-1990. Med J Aust. 1993;158:85-9.

18 Krishnamurthi RV, Barker-Collo S, Parag V, Parmar P, Witt E, Jones A, et al. Stroke incidence by major pathological type and ischemic subtypes in the Auckland Regional Community Stroke Studies: changes between 2002 and 2011. Stroke. 2018;49:3-10.

19 GBD 2016 Lifetime Risk of Stroke Collaborators; Feigin VL, Feigin VL, Nguyen G, Cercy K, Johnson CO, Alam T, et al. Global, regional, and country-specific lifetime risks of stroke, 1990 and 2016. N Engl J Med. 2018;379(25): 2429-37.

20 The World Bank. Data. World Bank Country and Lending Groups [accessed 2020 Feb https: //datahelpdesk.worldbank.org/knowledgebase/articles/906519-world-bank-countryand-lending-groups.

21 Lindeberg S, Lundh B. Apparent absence of stroke and ischaemic heart disease in a traditional Melanesian island: a clinical study in Kitava. J Intern Med. 1993;233(3):269-75.
22 Lindeberg S, Berntorp E, Carlsson R, Eliasson $\mathrm{M}$, Marckmann P. Haemostatic variables in $\mathrm{Pa}$ cific Islanders apparently free from stroke and ischaemic heart disease: the Kitava study. Thromb Haemost. 1997;77(1):94-8.

23 Lindeberg S. Stroke in Papua New Guinea. Lancet Neurol. 2003;2(5):273.

24 Maharaj JC, Venketasubramanian N. Burden of stroke in Fiji. Int J Stroke. 2010;5(4):321-2.

25 Maharaj JC, Reddy M. Young stroke mortality in Fiji Islands: an economic analysis of national human capital resource loss. ISRN Neurol. 2012;2012:802785.

26 Gloede TD, Halbach SM, Thrift AG, Dewey HM, Pfaff H, Cadilhac DA. Long-term costs of stroke using 10-year longitudinal data from the North East Melbourne Stroke Incidence Study. Stroke. 2014;45(11):3389-94.

27 Scott WG, Scott H. Ischaemic stroke in New Zealand: an economic study. N Z Med J. 1994; 107(989):443-6.

28 Kim J, Andrew NE, Thrift AG, Bernhardt J, Lindley RI, Cadilhac DA. The potential health and economic impact of improving stroke care standards for Australia. Int J Stroke. 2017;12(8): 875-85.

29 Te Ao B, Brown P, Fink J, Vivian M, Feigin V. Potential gains and costs from increasing access to thrombolysis for acute ischemic stroke patients in New Zealand hospitals. Int J Stroke. 2015;10(6):903-10.

30 Feigin VL, Krishnamurthi R, Barber PA, Arroll B. Stroke prevention in New Zealand: Can we do better? Int J Stroke. 2014;9(1):61-3.

31 Cadilhac DA, Carter R, Thrift AG, Dewey HM. Organized blood pressure control programs to prevent stroke in Australia: Would they be cost-effective? Stroke. 2012;43(5):1370-5.

32 Feigin VL, McNaughton H, Dyall L. Burden of stroke in Maori and Pacific peoples of New Zealand. Int J Stroke. 2007;2(3):208-10.

33 McNaughton H, Weatherall M, McPherson K, Taylor W, Harwood M. The comparability of resource utilisation for Europeans and non-Europeans following stroke in New Zealand. N Z Med J. 2002;115(1149):101-3.

34 Sandiford P, Selak V, Ghafel M. Are ethnic inequalities in 30-day ischaemic stroke survival emerging as treatment becomes more effective? N Z Med J. 2016;129(1437):8-14.

35 ARCOS IV Group; Feigin VL, Krishnamurthi RV, Barker-Collo S, McPherson KM, Barber PA, Parag V, et al. 30-year trends in stroke rates and outcome in Auckland, New Zealand (1981-2012): a multi-ethnic population-based series of studies. PLoS One. 2015;10:e134609.

36 Tiedeman C, Suthers B, Julien B, Hackett A, Oakley P. Management of stroke in the Australian indigenous population: from hospitals to communities. Intern Med J. 2019;49(8):962-8.

37 Balabanski AH, Newbury J, Leyden JM, Arima $\mathrm{H}$, Anderson CS, Castle S, et al. Excess stroke incidence in young aboriginal people in South Australia: pooled results from two populationbased studies. Int J Stroke. 2018;13(8):811-4.
38 Zhao Y, Guthridge S, Falhammar H, Flavell H, Cadilhac DA. Cost-effectiveness of stroke care in Aboriginal and non-Aboriginal patients: an observational cohort study in the Northern territory of Australia. BMJ Open. 2017;7(10): e015033.

39 Fearnley E, Li SQ, Guthridge S. Trends in chronic disease mortality in the Northern Territory Aboriginal population, 1997-2004: using underlying and multiple causes of death. Aust N Z J Public Health. 2009;33:551-5.

40 Available form: https://www.un.org/development/desa/pd/sites/www.un.org.development. desa.pd/files/files/documents/2020/Jan/ un_2019_worldpopulationageing_report.pdf Accessed 2020 Aug 10.

41 Available form: https://unstats.un.org/home/ Accessed 2020 Aug 10.

42 Friedlaender JS, Friedlaender FR, Reed FA, Kidd KK, Kidd JR, Chambers GK, et al. The genetic structure of Pacific Islanders. PLoS Genet. 2008;4(1):e19.

43 Horwood PF, Tarantola A, Goarant C, Matsui M, Klement E, Umezaki M, et al. Health challenges of the Pacific Region: insights from history, geography, social determinants, genetics, and the microbiome. Front Immunol. 2019;10: 2184.

44 Commonwealth Health Online [Internet] [accessed 2020 Aug 10]. Available from: http: //www.commonwealthhealth.org/?s=\& submit=Search - .

45 Stroke Foundation. National stroke audit acute services report 2019. Melbourne, Australia 2020 Oct

46 Liu Q, Ranta AA, Abernethy G, Barber PA. Provision of stroke thrombolysis services in New Zealand: changes between 2011 and 2016. N Z Med J. 2017;130(1453):57-62.

47 Burnell AL, Ranta A, Wu T, Fink J, McGuinness B, Caldwell J, et al. Endovascular clot retrieval for acute ischaemic stroke in New Zealand. N Z Med J. 2018;131(1484):13-8.

48 Child N, Barber PA, Fink J, Jones S, Voges K, Vivian M. New Zealand national acute stroke services audit 2009: organisation of acute stroke services in New Zealand. N Z Med J. 2011; 124(1340):13-20.

49 Quigley R, Mann J, Robertson J, Bonython-Ericson S. Are we there yet? Exploring the journey to quality stroke care for Aboriginal and Torres Strait Islander peoples in rural and remote Queensland. Rural Remote Health. 2019;19: 4850.

50 Mahon S, Krishnamurthi R, Vandal A, Witt E, Barker-Collo S, Parmar P, et al. Primary prevention of stroke and cardiovascular disease in the community (PREVENTS): methodology of a health wellness coaching intervention to reduce stroke and cardiovascular disease risk, a randomized clinical trial. Int J Stroke. 2018; 13(2):223-32

51 Harwood M, Weatherall M, Talemaitoga A, Barber PA, Gommans J, Taylor W, et al. Taking charge after stroke: promoting self-directed rehabilitation to improve quality of life-a randomized controlled trial. Clin Rehabil. 2012;26: 493-501. 